\section{AMERICAN-EURASIAN JOURNAL OF SUSTAINABLE AGRICULTURE}

ISSN: 1995-0748, EISSN: 1998-1074

2019, volume (13), issue (3): pages (1-9)

DOI: 10.22587/aejsa.2019.13.3.1

Published Online in September http://www.aensiweb.com/AEJSA/

\title{
Yield Optimization for Organic Greenhouse Cucumber Production
}

\author{
Zainab Abdel Mo'ez Embaby ${ }^{a}$, Muhammad Ali Rushdi ${ }^{b}$, Khaled El Sayed Abd El Mowla

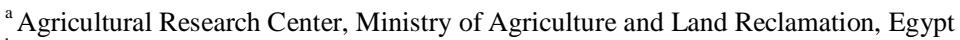 \\ ${ }^{\mathrm{b}}$ Department of Biomedical Engineering and Systems, Cairo University, Egypt
}

Received date: 12 July 2019, Accepted date: 28 September 2019, Online date: 4 October 2019

Address for Correspondence:

Zainab Embaby, Agricultural Research Center, Ministry of Agriculture and Land Reclamation, Egypt

E-mail: zainab.embaby@yahoo.com

Copyright () 2019 by authors and American-Eurasian Network for Scientific Information.

This work is licensed under the Creative Commons Attribution International License (CC BY).

http://creativecommons.org/licenses/by/4.0/

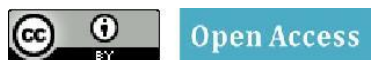

\begin{abstract}
Organic greenhouse cucumber (cucumis sativus L.) can be considered as one of several approaches to sustainable agriculture. It is more economic than conventionally grown cucumber crops. The main objective is to optimize yield and decrease costs. In general, excess in agricultural production on a reasonable basis and at a competitive price is vital to becoming better the farmers' economic situation. We introduce Weighted Goal Programming (WGP) as an efficient model in reaching optimality, involving net return, regular labor cost, crop collection cost, engineering supervision cost and seeds cost. The result revealed that the yield for cucumber crop in both greenhouse and open field covered its actual costs of production. Irrespective of the factors affecting the cucumber growth, the first optimization results are WGP model achieves the unique optimal solution for the overall problem, in greenhouse $x=165.1883$ tons/acre in spring, 50.00 tons/acre in autumn, and in open field $x=13.8796$ tons/acre in spring, 10.4640 tons/acre in autumn. This study concluded that the cucumber greenhouse system has been shown to have higher profitability than the open-field system and is more efficient which compensates its extra costs. A marketing aspect study was suggested as it could open up more avenues for improving the performance of this organic greenhouse production system as an essential sub-sector.
\end{abstract}

\section{KEYWORDS}

Organic greenhouse cucumber, Weighted Goal Programming, Optimization

\section{INTRODUCTION}

Organic agriculture seems a form of sustainable or ecological agriculture that involves production according to precise standards. It can be considered as a holistic system based on traditional agriculture and utilizes both traditional and scientific knowledge. According to UNCTAD studies [1] organic agriculture is a good option for food security in Africa, increased earnings, and reduced independence on external inputs. It achieves a range of environmental benefits as it does not pollute the environment, conserves biodiversity and natural resources, mitigates climate change by using less energy than conventional agriculture and protects farmers' abundant traditional knowledge as well traditional agricultural varieties [1]. Organic greenhouse vegetable production is one of the most prominent agricultural activities. It offers off-season cultivation of vegetables. Cucumber (cucumis sativus L.) is one of the popular vegetable crops grown widely throughout the world. Organic greenhouse cucumber is more economical than conventionally grown cucumber crops. The main objective of agricultural production is to increase yield and decrease costs. In general, increases in agricultural production on a sustainable basis and at a competitive price are vital to improving the farmer's economic condition [2]. A greenhouse grower would like to reasonably utilize available resources (human labor, 
machinery, diesel fuel, water for irrigation, electricity and seed energy etc.) to maximize productivity with minimal cost and environmental impact [3].

Moreover, production of organic cucumber in greenhouses has led to the minimum use of chemical fertilizers and pesticides, which is not possible under open-field conditions. Besides, the greenhouse technology offers a favorable environment for cucumber growth and production: it is more profitable, and the cucumber yield can be increased by many folds as compared to that in open-field cultivation. The results revealed the importance of the economic analysis of organic cucumber production in a protective structure to compare the profitability of production with open-field conditions [4]. Tuzel et al. [5] proved that biological control has an important role in organic agriculture, particularly in greenhouses.

The results indicated that organic greenhouse cucumber production has a less environmental impact and is more economic than conventional bag culture, due to reduced chemical input and reduced operating and initial investment costs. Since the nutrient requirement of the crops is not minerally provided in organic production, yield reduction is inevitable, due to the limitation imposed by international regulations [5]. The authors highlighted that further studies might be required to optimize organic production as new solutions, changes or alternatives take place in the related regulations. Also, they showed that the most important step in transition to organically grown greenhouse vegetables lies in the farmers' willingness to accept and get training [5]. According to Rohaeni et al., it is necessary to optimize patterns of sustainable crops by considering ecological, economic and socio-cultural aspects in dryland [6]. Production planning is a complex task since decisions have to be taken considering input and output physical relations, natural farm resources, input and output cost-price ratios and also farmer's preferences. Besides, the previous studies [7] confirmed that possible alternatives at the level farm as well as in the analysis of decision making can be mathematical programming models as an imperative one. The goal programming (GP) techniques can be used to overcome problems in determining optimal cropping patterns by considering multiple objectives in agricultural planning and management [7]. In such models, agricultural production goals can be measured using positive and negative deviation variables defined for each goal separately, preventing either over - or underachievement of the goal. As well as, the author [7] clarified that the relative importance of each deviation variable is determined by weights in the objective function. However, results of earlier studies show that a single-objective decision-making process, based on the maximization of the expected income might be biased and does not necessarily lead to the bestachievable option of the analyzed farm [7]. The reason for using multiple criteria decision making (MCDM) lies in supporting decision-makers who have decision and planning problems involving multiple conflicting criteria. GP seeks 'satisfaction' rather than 'optimization'. Recently, there has been a clear shift toward the use of weighted goal programming (WGP) in agricultural resource management [8]. For example, the work of Memarian et al. [8] revealed that WGP forms a single-objective function as the weighted sum of various objective functions as input reduction and income generation. Optimal decisions need to be taken in the presence of trade-off between two or more conflicting objectives, then weighted or non-preemptive goal programming (WGP) should be used. The weighting of deviational variables at the same priority level shows the relative importance of each deviation. Besides, Orumie et al. clarified that deviational variables measured in different units cannot be added because of the principles of incommensurability [9]. For successful adoption and transition to greenhouse organic cucumber business, Ghorbani [10] argued that programs supporting farmers to produce greenhouse organic cucumber must emphasize multiple components especially price, insurance, technical-agronomic aspects, educational aspects, credit and market supports. In addition, supporting policies are made either indirectly through support of research, extension, or directly through financial incentives. Authors' arguments on policies supporting organic farming include two major reasons: its production considers public goods, or/ and it can be seen as a market opportunity [10]. The reasons for low prices of open-field cucumber particularly in the summer season are the less fruit uniformity (shape and color) due to the effects of weather and agricultural practices [11]. Also, farmers who produce high-quality greenhouse cucumbers acquire a high annual average price per kilogram of product. Thus, a significant number of cucumber farmers in Egypt changes to greenhouse production of cucumber [11]. This work aims to examine the optimization model of the present yield of organic cucumber in Ismailia and El-Behira governorates in Egypt, using a WGP approach and sensitivity analysis. The model can be combined with adaptive weights of deviational variables as the fit measure. In order to obtain all possible solutions, sensitivity analysis on different weight structures for the goals as specified by the decision-maker has been performed. Also, economic analysis to compare open-field and greenhouse organic cucumber production and the profitability of the crop has been performed.

\section{KEY PROBLEM}

Population crisis and limited production resources have an impact on agriculture, both in terms of land-use management and in terms of pollution created. The intent of the green revolution was to obtain higher levels of crop production to fulfil the world growing population's need for food. To meet growing consumption of fresh cucumber with the limited cultivated area, optimization of yield is one of the best solutions to treat this problem. 
In Egypt, the population grew from 80 million people in 2011 to 89 million in 2015, giving an increase of 11\% [12]. The production of fresh cucumber in open-field in 2011 was 795 thousand tons but decreased to 634 thousand tons in 2015 [12], giving a decrease rate of 20\%. The gap between domestic production and population needs can be narrowed by using greenhouse technology in cultivation. According to the previous studies, the greenhouse production of organic cucumber can be increased by many folds as compared to that in open-field system cultivation. The harvested area dedicated to cucumber from 2011 to 2016 failed to regain its momentum. The specific problem addressed by this research is that there are limited scientific researches for optimization of organic cucumber yield in greenhouses to support management decisions.

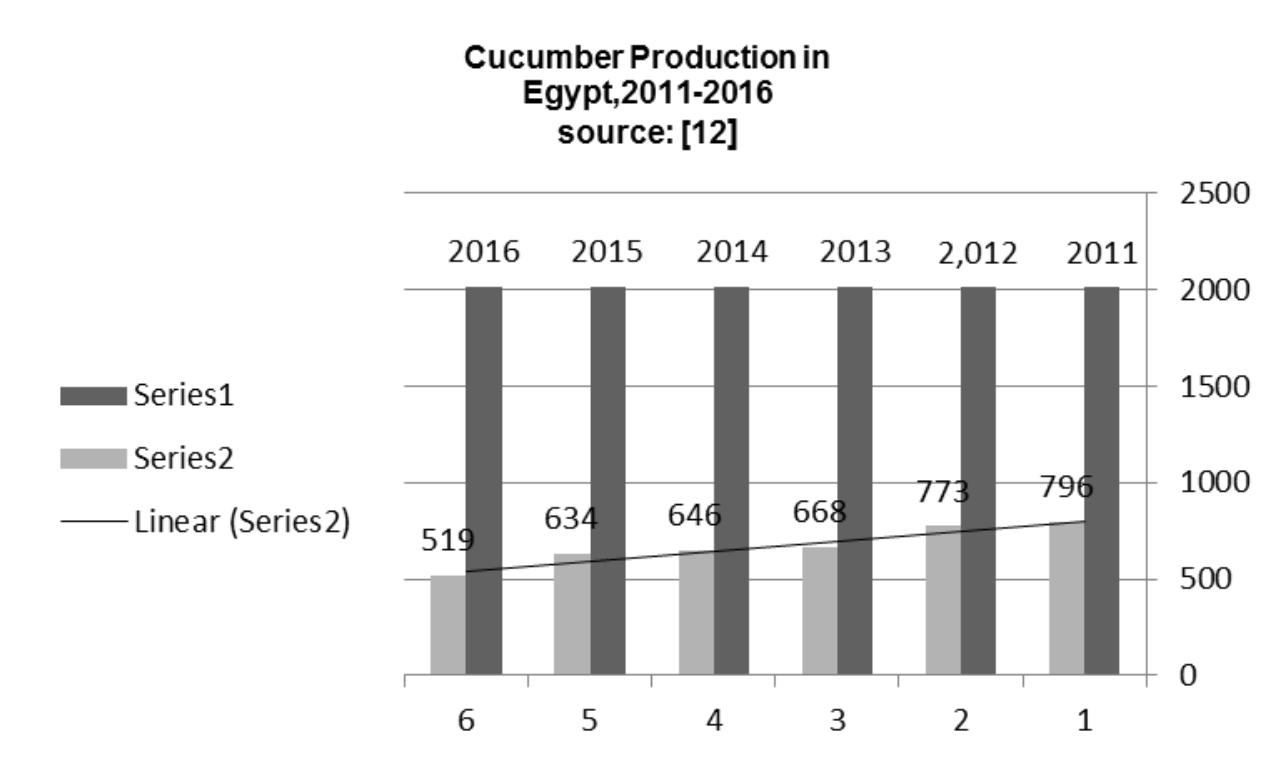

Fig.1: Cucumber Production in Egypt from 2011-2016. Source: [12] Food Balance 2016 - Economic Affairs, Agriculture and Land Reclamation Ministry, Egypt.

\section{Cucumber production in 12 Leading countries and the world,2016 Source:[15]}

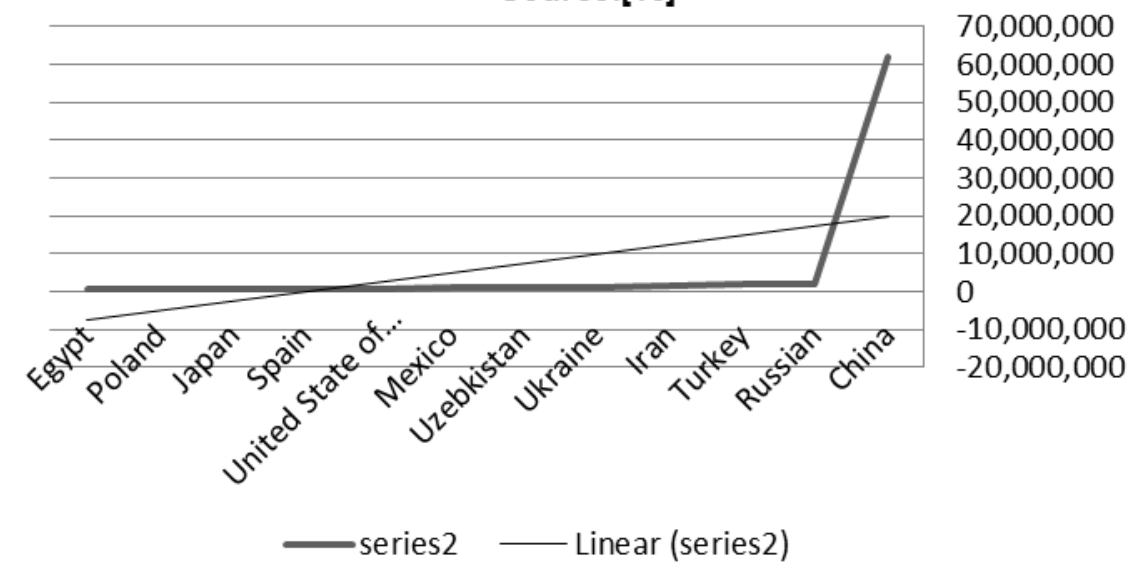

Fig. 2: cucumber production in 12 leading countries and the world, 2016. Source: 15 $\underline{\text { www.fao.org }}$

\section{METHODOLOGY}

In the following, we present some characteristics of this research which distinguished from those available in the referenced literature herein studies:

a. Integration between production planning and economic analysis.

b. Problem Identification.

c. Data Collection. 
d. Modelling. A WGP model was developed for optimization cucumber yield.

e. Model Solution. It was utilized to achieve the objective of optimization.

f. Results Validation. Experts from Agricultural Research Center were consulted on the validity of the results.

Figure (1) shows cucumber production in Egypt from 2011-2016. Figure (2) highlights cucumber production in 12 leading countries and the world.

\subsection{Location and Time of the Research}

The study was conducted in Ismailia and El-Behira governorates in Egypt. The data was collected over the 2016/2017 spring and autumn seasons.

\subsection{Sampling Techniques and Data Collection}

Purposive Sampling was the best choice because the respondents were selected deliberately to provide valuable information that cannot be obtained from other choices. The selected respondents were the one having or running an organic cucumber and conventional cucumber in greenhouses and open fields. The number of the respondents was determined by 30 producers of each system (greenhouse and open field). Then the size of the sample was 60 producers. The method used in this study was a survey method. The primary data were obtained from interviews with farmers. The secondary data was collected from related offices/agencies. The average size of the studied area has been found to be one acre. The variables examined for the analysis of goal programming included fixed costs and variables costs, the yield of acre, ton cost/crop of each season, selling price average, total return, net return and Invested Egyptian pound return.

\subsection{Analysis of Data.}

Weighted goal programming applies linear programming to achieve the goals subject to changing objectives constrained by adding slacks and other variables representing a deviation from the goal. The defined approach is WGP [13]. The WGP formulation is defined as below:

It is $n$ variables; $m$ goal constraints; $t$ deviational variables and $F$ weight factors that include the rigid constraints.

The objective function $\mathrm{z}$ for yield optimization for organic greenhouse cucumber production:

$\operatorname{Min} \mathrm{z}=\sum_{f}^{p}\left(w_{f}^{-} d_{i t}^{-}+w_{f}^{+} d_{i t}^{+}\right)$

Such that

$\sum_{i}^{m} a_{i j} x_{j}+d_{i}^{-}-d_{i}^{+}=b_{i}$

$\sum_{j} a_{i j} x_{j} \leq b_{i}$

Where

$\mathrm{f}>=0, \quad x_{j}, d_{i}^{-}, d_{i}^{+}>=0$

for $(\mathrm{i}=1,2, \ldots \ldots m ; \mathrm{j}=1,2,3, \ldots . n)$.

$w_{i} \geq 0, x_{j}, d_{i}^{-}, d_{i}^{+} \geq 0, x_{i j}, d_{i}^{-}, d_{i}^{+} \geq 0$

Note that $w_{i}=\mathrm{f}^{\text {th }}$ weighted factor $\mathrm{f}=1,2 \ldots F$,

$\left(w_{f}^{-} d_{i f}+w_{f}^{+} d_{i f}^{+}\right)$are set of the weighted sum of the deviational variables in $z$. The weighted factors $w_{f}$ for the deviational variable [8].

As a measure of sensitivity, the problem is solved using different weight structures specified by the decision-maker. The yield optimization in this situation was formulated as a Weighted Goal Programming (WGP) problem. The solution of the WGP problem was implemented by using Matlab R2016. In the WGP problem, the objective of optimization to be achieved is a constraint. Therefore, the objective of the optimization in this study is treated as a goal constraint. The WGP problem is formulated to achieve several objectives including several alternative activities and resource constraints analysed at the farm level.

Formulating the WGP model involves the following steps:

a) Determine decision variables;

b) Constraint function formulation;

c) Determine goal functions;

d) Weighted goal programming function formulation.

\section{MODEL FORMULATION}

In this paper, the problem is formulated as a multi-objective programming problem, in which the decisionmakers have two objectives. The first one is to maximize the net return of cultivating organic cucumber, and the second one is to minimize the cost of regular labour. 
4-1 Notations

We list below the input parameters, constraints, and the objective function of the yield optimization model of organic greenhouse cucumber:

$\mathrm{C}_{\mathrm{j}} \quad$ index of crop; $\mathrm{j}=1$ organic, 2 conventional,

$\mathrm{S}_{\mathrm{i}} \quad$ season; $\mathrm{i}=1$ spring, 2 autumn,

$\mathrm{X}_{\mathrm{cs}}$ yield average of each season,

$\mathrm{Tx}_{\mathrm{cs}}$ Total yield of crop,

$\mathrm{N}_{\mathrm{cs}}$ Net return of crop $\mathrm{c}_{\mathrm{i}}$ in season $\mathrm{s}_{\mathrm{i}}$,

$\mathrm{N}$ Expected net return,

$\mathrm{S}_{\mathrm{cs}}$ Selling price of each crop,

$\mathrm{R}_{\mathrm{cs}}$ Return of crop,

$\mathrm{R}$ Expected return,

TL Expected labour cost of each season (man/h.),

$\mathrm{L}_{\mathrm{c} / \mathrm{s}} \quad$ Labour cost /season (man/h.),

I Invested Egyptian pound return/crop of each season,

TI Total expected invested Egyptian pound return,

$\mathrm{C}_{\mathrm{cs}}$ Ton cost/crop of each season,

TC Total cost,

$\mathrm{S}_{\text {/cs }}$ Seeds price,

TS Total seeds cost.

$\mathrm{E}_{\mathrm{cs}}$ Engineering supervision/crop of each season,

TE Expected engineering supervision,

$\mathrm{CC}_{\mathrm{sc}}$ Crop collection cost/unit of the season

$\mathrm{T}_{\mathrm{cc}}$ Total collected crop,

$\mathrm{W}_{\mathrm{cs}}$ Cost of irrigation,

TW Total cost of irrigation,

BEP Break-even Point (Total cost of production $\div$ Price per unit of yield).

\section{4-2 Decision Variables}

$x_{c s}$ is the variable which denotes the number of cucumber crop units produced from one acre per season. For the proposed problem, there is a need to satisfy the self-sufficiency and export of organic cucumber.

\section{4-3 Multi-objective Optimization Modelling Formulation}

In formulating the yield optimization problem of organic greenhouse cucumber in a year, the total time period is divided into two seasons according to the climate conditions. Notations used to formulate the WGP model of the problem were defined before based on the decision maker's objectives in the proposed problem and the notations mentioned above. According to a new approach introduced by Orumie [13], this study develops a new algorithm to solve the proposed problem.

\section{5- GOALS}

In this study, the first objective function is maximized to make sure that the production process can be carried smoothly:

1. To increase net return.

By multiplying yield of an acre by net return/unit:

Max Z $=\sum_{i=1}^{g} \sum_{c=1}^{e} N_{c s} x_{c s} \geq \mathrm{N}$

2. To reduce regular labour cost this will be counted as the basic economic aid to the organic cucumber farmers. By multiplying yield of an acre by the cost of labour/unit:

Min $\mathrm{Z}=\sum_{\mathrm{i}=1}^{g} \sum_{c=1}^{e} L_{c s} x_{c s} \leq \mathrm{TL}$

\section{6 - CONSTRAINTS}

Generally, some compulsory conditions must be fulfilled when the decision-maker takes the decision. Functional constraints are constraints limiting the realizations of the goals. In this research, the required conditions are listed below:

The first constraint minimizes crop collection cost/unit.

By multiplying unit of crop collection cost by the number of produced tons/season: $\operatorname{Min} \mathrm{Z}=\sum_{i=1}^{g} \sum_{c=1}^{e} C C_{c s} x_{c s} \leq \mathrm{TCC}$

The second constraint reduces engineering supervision cost per produced unit /season. By multiplying cost of engineering supervision of one unit by the cost of produced units: 
$\operatorname{Min} \mathrm{Z}=\sum_{\mathrm{I}=1}^{g} \sum_{c=1}^{e} E_{c s} \quad x_{c s} \leq \mathrm{TE}$

The third constraint states that seed cost should be less than the available cost/ season By multiplying cost of seeds of one unit by units produced/season:

$\operatorname{Min} \mathrm{Z}=\sum_{i=1}^{g} \sum_{c=1}^{e} S_{c g} x_{c s} \leq \mathrm{TS}$

It is not simple to find an optimal solution for a multi-objective optimization model. In such kind of problems, we need to assign a weight to each objective for normalization. So, in this study, the weighted sum method is adopted to solve the multi-objective optimization problem. Suppose that $w_{i}$ is a deviation variable for $f_{i}(y)$ objectives functions and the sum of $w_{i}$ will be equal to 1 . Weights express the importance of objective functions in the proposed model. The model can be converted into a single objective using the following process. According to the WGP approach, the weighted equation form can be written of the given problem as:

Min $Z=w_{1}\left(d_{1}^{+}+d_{1}^{-}\right)+w_{2}\left(d_{2}^{+}+d_{2}^{-}\right)$

s.t

$\sum_{i}^{m} a_{i j} x_{j}+d_{i}^{-}-d_{i}^{+}=b_{i} \quad i=1,2, \ldots \mathrm{m}$

$\sum_{j}^{n} c_{i j} x_{j} \leq h_{i}$

and $x_{j}, d^{-}, d^{+} \geq 0$

for $(i=1,2, \ldots ., m: j=1,2,3 \ldots ., n)$

$\mathrm{Z}=$ objective function $=$ Summation of all deviations variables

$\sum_{j}^{n} a_{i j}$ is the linear function on the left-hand side of the the $i^{\text {th }}$ goal constraint. $x_{j}$ is a decision variable, $a_{i j}$ represents the coefficient of the $j^{\text {th }}$ decision variable, $c_{i j}$ is the linear function on the left-hand side of $i^{\text {th }}$ rigid constraint. . $b_{\mathrm{i}}$ is the right-hand side constant of the goal constraint $\mathrm{i}$. $h_{\mathrm{i}}$ is the right-hand side constant of the rigid constraint $\mathrm{i}$.

The objective function is a set of the weighted sum of the deviational variables. The parameter $w_{i}, i=1,2$, $\ldots \mathrm{n}$, are positive numerical weights that reflect the decision maker's preferences regarding the relative importance of each goal. The determination of the specific values of these weights is subjective, where $w_{i}^{+}$and $w_{\mathrm{i}}^{-}$represent weights associated with positive and negative of each goal corresponding to to $D_{\mathrm{i}}^{+}$and $D_{\mathrm{i}}^{-}$that are, respectively, positive and negative deviations with respect to the aspirational goal levels. The interpretation of the model is quite straightforward: the smaller the deviations from the desired goals the better the solution.

Practical Application and Sensitivity Analysis

Min $\mathrm{Z}=w_{1}\left(d_{1}^{+}+d_{1}^{-}\right)+w_{2}\left(d_{2}^{+}+d_{2}^{-}\right)$where $\left(w_{1}=7\right.$ and $\left.w_{2}=-5\right)$

s.t

$4140 \mathrm{x}_{\mathrm{cs}}+w_{1} d_{1}^{-}=298080$

$600 \mathrm{x}_{\mathrm{cs}}+w_{2} d_{2}^{+}=48000$

$250 \mathrm{x}_{\mathrm{cs}} \geq 18000$

$230 x_{\mathrm{cs}} \geq 16500$

\section{RESULTS AND INTERPRETATION}

Putting the above numerical information into the presented model, we followed WGP by using Matlab $\mathrm{R} 2016 \mathrm{~b}$ for testing the effectiveness of the model. We got a satisfactory solution based on WGP. The best results are presented in Table 1. The optimal solution depends on the value of $x$ and the different weights assigned to both objectives. The values of the weights of deviations are based on their rank. The higher the rank, is the higher the value of the weight. The decision-maker can get different objective values by changing these parameters. The results in Table 1 can be interpreted as follows:

Table (1) Organic cucumber in the greenhouse and open field

\begin{tabular}{|c|c|c|c|c|c|c|}
\hline \multirow[b]{5}{*}{ Organic Cucumber } & \multirow{3}{*}{$\begin{array}{l}\overline{0} \\
\overline{0} \\
\overline{0} \\
0 \\
0\end{array}$} & Season & $\mathrm{X}$ & $\frac{d_{1}^{-}}{-1}$ & $d_{2}^{+t}$ & Fval \\
\hline & & Spring & 165.1883 & 0.0454 & 0.000 & 0.3178 \\
\hline & & Autumn & 50.000 & 0.000 & 0.000 & $2.4435 \mathrm{e}-13$ \\
\hline & \multirow{2}{*}{ 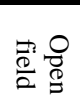 } & Spring & 13.8796 & 3.4821 & 0.000 & 24.3745 \\
\hline & & Autumn & 10.4640 & 0.000 & 0.000 & $-7.7666 e-05$ \\
\hline
\end{tabular}


Regarding net return, a negative deviation of $d_{1}^{-}=(0.0454)$ with respect to current net return, implies that there is a high underachievement. The solution falls short of the first goal (net return $\geq 296000,153370$ respectively, by just $0.0454,3.4821$. From the cost perspective, it can be seen that costs reach the optimal result but did not exceed the target. The solution $\boldsymbol{d}_{2}^{+}=0$ shows that G2 is fully satisfied and the WGP model ensures that goal 2 is optimum. To ascertain the achievement of optimized result towards what should be reached, this can be seen from the deviation variable value in Table 1 because the goal of WGP is to minimize deviation variable value. If the deviation variable is zero, it can be said that the goal is reached. In contrast, when the deviation variable becomes greater, goal achievement sounds smaller. WGP model achieves the unique optimal solution for the overall problem, in greenhouse $x=165.1883$ tons/acre in spring, 50.00 tons/acre in autumn, and in open field $x$ $=13.8796$ tons/acre in spring, 10.4640 tons/acre in autumn.

As compared to open field, the greenhouse cucumber has the advantageous high yield, seasonal availability and its fruit quality including fruit uniformity, color and firmness. The reasons for low yield of open field cucumber (in particular summer season) are due to weather and agricultural practices. Also, farmers who produce high-quality greenhouse cucumbers acquire a high annual average price per kilogram of product.

Growing cucumbers in the greenhouses and in accordance with the principles of organic farming are the main conditions for higher prices in the market. The highest total costs (208000.00 Egyptian Pound/acre) in spring but also the highest gains (504000.00 Egyptian Pound/acre) were realized in producing slicing cucumber both in the greenhouse in the organic farming system.

Irrespective of the factors affecting the cucumber growth, the yield under protective cultivation can increase ten times as compared to that in open-field cultivation as reported by numerous authors in the past [6]. Regarding the sum of deviation, Table (1), the sum of deviation is 24.3745 ; it means that there is a high deviation between goals and decision variables achievement.

Economic Analysis

Economic analysis is an essential aspect as it provides an accurate picture of how cultivation under greenhouses is faring compared to the open-field cultivation [11].

Table (2): The economic comparison of greenhouse and open-field cucumber production systems

\begin{tabular}{|l|l|l|l|l|}
\hline \multirow{2}{*}{ Item } & \multicolumn{3}{l|}{ Greenhouse } & Open-field \\
\cline { 2 - 5 } & Spring & Autumn & Spring & Autumn \\
\hline Variable Costs(A) & 145065 & 133695 & 60040 & 54285 \\
\hline Fixed Costs(B) & 62935 & 62935 & 9500 & 9500 \\
\hline Total Costs (A+B) & 208000 & 196630 & 69540 & 63785 \\
\hline Total Return & 504000 & 350000 & 96000 & 80000 \\
\hline Total Yield(ton) & 72 & 50 & 12 & 10 \\
\hline $\begin{array}{l}\text { Average Price of } \\
\text { LE/ton }\end{array}$ & 7000 & 7000 & 8000 & 8000 \\
\hline Gross Margin & 358935 & 216305 & 35960 & 25715 \\
\hline Net Return & 296000 & 153370 & 26460 & 16215 \\
\hline $\begin{array}{l}\text { Break-even } \\
\text { Point(BEP)ton }\end{array}$ & 29.71 & 28.09 & 8.69 & 7.97 \\
\hline
\end{tabular}

The result revealed that the break-even point for cucumber cultivation under green-houses was in spring and autumn seasons about 29.71 and 28.09 tons, respectively. This means that the average yield of greenhouse cucumber in the study area (one acre) is higher by 42.29 tons $(72-29.71=42.29)$ and 21.91 tons $(50$ $28.09=21.91$ ) while it was under open field 8.69 and 7.97 tons, respectively. This means that the average yield in spring and autumn seasons is higher by 3.31 tons $(12-8.69=3.31)$ and 2.03 tons $(10-7.97=2.03)$, respectively.

Therefore, this outcome points out that the yield for cucumber crops in both greenhouse and open field covered its actual costs of production. On top, the results show that both systems were able to recover all the total production costs in terms of variable as well as fixed costs. The cucumber greenhouse system has been shown to have higher profitability than the open-field system and is more efficient which compensates its extra costs. Previous studies reported that the production of cucumber in the greenhouses is hard and risky business and the lack of marketing experiences and levels of required skills grow up the break-even point under intensively greenhouse conditions which were reported as main problems of the greenhouse production of organic cucumber [11]. 
Table 3: Sensitivity analysis results in organic greenhouse cucumber production system

\begin{tabular}{|c|c|c|c|c|c|c|}
\hline \multirow{6}{*}{$\begin{array}{l}\text { Organic } \\
\text { cucumber }\end{array}$} & \multirow{4}{*}{ Greenhouse } & \multirow[b]{2}{*}{ Season } & \multirow[b]{2}{*}{$\begin{array}{ll}\text { Our } & \text { case } \\
\text { Yield }(x) & \end{array}$} & \multicolumn{3}{|c|}{ Sensitivity Analysis } \\
\hline & & & & $\begin{array}{l}\text { Net return } \\
d_{1}^{-}\end{array}$ & $\begin{array}{l}\text { Regular labor cost } \\
d_{2}^{+}\end{array}$ & Fval \\
\hline & & Spring & 120.339 & 25.4956 & 0.0357 & 229.1395 \\
\hline & & Autumn & 50.000 & 0.000 & 0.000 & $1.09390-12$ \\
\hline & Open field & Spring & 13.3339 & 2.9127 & 0.000 & 26.2141 \\
\hline & & Autumn & 10.3189 & 0.000 & 0.000 & $\begin{array}{l}-2.7198 \mathrm{e}- \\
05\end{array}$ \\
\hline
\end{tabular}

Sensitivity analysis was formulated to see which solution(s) come closest to satisfying the set of goals. The global market is becoming more and more competitive day by day. Due to this reason, decision-makers face rigorous challenges for achieving food safety in an efficient and cost-effective manner. We carried out the sensitive analysis by changing the decision maker's confidence level based on Saaty Scale [14], and by increasing the weighted sum of deviational variables; net return and regular labour cost. The solution is shown in Table 3. The interpretation of the model: the smaller the deviations from the desired goals the better the solution. In the first case (increasing the weighted sum of deviation variables of net return to be 9 instead of 7 , and regular labour cost to be -9 instead of -5 ), we have obtained a yield value of 120.339 L.E. The implication is those yield parameters are highly sensitive to changes in the net return and regular labour cost. A marketing aspect study is suggested as it could open up more avenues for improving the performance of this organic greenhouse production system as an important sub-sector. Figure 1 shows that there is a deficiency in cucumber production in Egypt and Figure 2 highlights the world level, Egypt sounds the least productive which necessarily entails optimization of greenhouse cucumber production.

\section{CONCLUSION}

Population crisis and limited production resources have an impact on agriculture, both in terms of land-use management and in terms of pollution created. Weighted goal programming (WGP) techniques enable one to optimize several objectives at once. Crucial objectives that are usually in contradiction might be converted to goals and the remainder of the objectives can be considered as constraints (Zgajnar et al.,2011) WGP forms a single objective function as the weighted sum of various objective functions, the weights are assigned according to Decision Maker's(DM's) preferences. These weights are allocated with the help of favourites and which goal has the highest important than others. If the decision-maker is more interested in direct comparisons of the objectives, then weighted goal programming (WGP) should be used. This work aimed at optimizing the present yield of organic greenhouse cucumber in Ismailia and El-Behira governorates.

a) The first optimization results are WGP model achieves the unique optimal solution for the overall problem, in greenhouse $x=165.1883$ tons/acre in spring, 50.00 tons/acre in autumn, and in open field $x=13.8796$ tons/acre in spring, 10.4640 tons/acre in autumn Table 1.

b) The cucumber greenhouse system has been shown to have higher profitability than the open-field system and is more efficient which compensates its extra costs Table 2. Economic analysis is an essential aspect as it provides an accurate picture of how cultivation under greenhouses is faring compared to the open-field cultivation (Diab et al.,2016).

c) Yield parameters are highly sensitive to changes in the net return and regular labor cost. A marketing aspect study is suggested as it could open up more avenues for improving the performance of this organic greenhouse production system as an essential sub-sector.

d) Experts' team supported the results. And the results of this study are promising and encourage other research efforts.

\section{RECOMMENDATIONS}

- Increased support for organic greenhouse cucumber on the level of small farmers.

- Expanding the markets of organic greenhouse cucumber.

\section{REFERENCES}

[1] UNCTAD (2009). Sustaining African Agriculture Organic Production. ( $N^{\circ}$ 6/Rev.1, February 2009).

[2] Mohammadi A. Omid M. Economical analysis and relation between energy inputs and yield of greenhouse cucumber production in Iran. Applied Energy 2010: 87: 191- 196.

[3] Tavakoli Y. Khoshkam S. The Impact of Organic Fertilizers on Production of Organic Greenhouse Cucumber. Mediterranean Journal of Social Sciences 2013:4-14. 
[4] Singh M. C. Singh J.P. Pandey S.K. Mahay D. Shrivastva V. Factors Affecting the Performance of Greenhouse Cucumber Cultivation. International Journal of Current Microbiology and Applied Sciences 2017: 6(10):2304-2323.

[5] Tuezl Y. C. Orthan Gul A. Engindeniz S. Organic cucumber production in the greenhouse: A case study from Turkey. Renewable Agriculture and Food Systems 2005: 20(4): 206-213.

[6] Rohaeni E S. Hartono B. Fanani Z. Nugroho B. A. Optimizing Crop and Livestock Integration Using the Analysis Approach of Goal Programming (a case study in Tanah Laut Subdistrict, South Kalimantan, Indonesia). Journal of Economics and Sustainable Development 2014:5:1.

[7] Žgajnar J. Kavčič S. Weighted goal programming and penalty functions: whole-farm planning approach under risk. Paper prepared for presentation at the EAAE 2011 Congress. ETH Zurich, Zurich, Switzerland.

[8] Memarian H. Balasundram S. K. Abbaspour K. C. Talib J. B. Sung C. T. B. SOOD A. M. Integration of analytic hierarchy process and weighted goal programming for land use optimization at the water shed scale. Turkish Journal of Engineering \& Environmental Sciences 2014 : 38: 139-158.

[9] Orumie U. C. Ebong D. Another Efficient Method of Solving Weighted Goal Programming Problem. Asian Journal of Mathematics And Applications 2013: 105: 11.

[10] Ghorbani M. Supportive Policies of Greenhouse Organic Cucumber Production in Khorasan-Razavi Province. Asian Journal of Plant Sciences: 2009: 8 (1): 42-47.

[11]Diab A. A. Musa M. A. Abas H. S. Greenhouse grown Cucumber as an Alternative to Field Production and its Economic Feasibility in Aswan Governorate, Egypt. Assiut J. Agric. Sci., 2016:47(1):122- 135.

[12]Food Balance 2016 - Economic Affairs, Agriculture and Land Reclamation Ministry, Egypt

[13] Orumie, U.C. New Approach to Solving Generalized Linear Goal Programming Problem. Mathematics Applied in Science and Technology 2017:9 (1): 1-22.

[14] Saaty T. L. and Katz J. M. How to make a decision: The Analytic Hierarchy Process. European Journal of Operational Research 1990: 48: 9-26.

[15] www.fao.org.

\section{Acknowledgements}

We are thankful to the Editor-in-chief, Associate Editor, and anonymous referees for their valuable comments and suggestions to improve this paper. The first author thanks D. Muhammad Ali Rushdi for his cooperation. 